\section{Has the Child of Metallurgy Walked Out on Its Parent? Robert W. Cahn}

The following article is a shortened version of the Turnbull Lecture delivered at the 2002 Materials Research Society Fall Meeting on December 2 in Boston.

In 1958, the year most appropriately regarded as the birth year of materials science, Herbert Hollomon, one of its progenitors, remarked, "Out of metallurgy, by physics, comes materials science." If one looks dispassionately at the evolution of materials science and engineering (MSE) in its early years, the truth of that assertion is indisputable.

Nowadays, MSE can be classified in all sorts of ways. One basis is classification in terms of the type of chemical bondingmetallic, ionic, covalent, hydrogen-and in terms of the presence or absence of identifiable molecules. Another basis is in terms of broad categories of applicationstructural or functional. A third method is a refinement of the second-steels, creepresistant alloys, electrical conductors, superconductors, dielectrics, semiconductors. A fourth focuses on physical formscastings, thin films, sheet, filaments, quantum dots, confined heterostructures, fiber-reinforced composites. The first form of classification is closely allied to the most venerable of all kinds of subdivisions: between metals, ceramics, semiconductors, polymers, and composites.

My concern here is the question: Are metals and alloys, substances with metallic bonds, used in many physical forms, and representing a major part of the Periodic Table, to be regarded as materials, part of the modern domain of MSE? An absurd question? Unfortunately not. Consider, for a start, the names I have listed in Table I. Here, the category "materials" is apparently taken to not include metals, or at any rate, not all

Material Matters is a forum for expressing personal points of view on issues of interest to the materials community. aspects of metals; so, metals must be mentioned separately.

The stages in the changing balance between metals and other aspects of MSE are well summarized in the table of contents of a book by the late Michael B. Bever ${ }^{1}$ of the Massachusetts Institute of Technology (MIT), Metallurgy and Materials Science and Engineering at MIT: 1865-1988, written to commemorate the centenary of the first injection of metallurgy into a curriculum originally dominated by mining. Following an introductory chapter on "The Early Years," we have successive chapters on "Mining Engineering and Metallurgy: 1889-1916"; "Extending the Scientific Base: 1917-1938"; World War II: 1939-1946"; "The Postwar Period: 1946-1950"; "The Flowering of Metallurgy: 1951-1962"; "Metallurgy and Materials Science: 1962-1972"; and "Materials Science and Engineering: 1972-1988." This sequence maps in unmistakable fashion the rise, "flowering," and relative decline of metallurgy as the lead discipline in a technologyfocused institution.

It is clear enough that all these illogicalities derive from the fact that many organizations and periodicals that were once wholly focused on metals and alloys were converted, often against strong local resistance, to a materials science focus, and the changeover was never quite complete. One such resister, maybe the most resolute, was Robert Mehl, a most distinguished physical metallurgist, of the Carnegie Institute of Technology. When his university became the CarnegieMellon University, his department remained for a while one of metallurgy and materials science; some time after his death, it sighed deeply and converted itself into an MSE Department.

Mehl was not, fortunately, typical of the American intellectual aristocracy of our field. David Turnbull is one of the indisputable "greats" of our profession. "What profession?" some of you are perhaps inclined to ask. Well, Turnbull began as a physical chemist; for years he worked largely on metals and alloys (thus, a metallurgist); then for many further years he co-edited a famous serial published by Academic Press, Solid State Physics-so he must have been a physicist. To judge from the name of the laboratory at Harvard on which he has shed so much luster, maybe he is an engineer. In a 1983 essay about the development of materials science, Turnbull remarked, "interdisciplinary cooperation must continue and flourish if Materials Science is to remain a meaningful and viable superdiscipline",; so clearly, he is a materials scientist. The last, I submit, subsumes all the rest.

Another notable materials scientist (although he flourished at General Electric and won his Nobel Prize before materials science was thought of) was Irving Langmuir (1881-1957). He began as a metallurgist, but became a physical metallurgist under Walther Nernst's tutelage at Göttingen (PhD 1906, though he was criticized for an inadequate command of mathematics). Later, even without mathematical prowess, he became a surface chemist of genius. His trajectory was the opposite of Turnbull's.

A metallurgist of genius, the finest ever to have practiced in Russia/Ukraine, was

\section{Table I: Some Current Anomalies in Nomenclature.}

\section{Societies}

TMS: Minerals, Metals and Materials Society

SF2M: Société Française de Métallurgie et Materiaux

Academic Departments

Department of Materials Science and Metallurgy (Cambridge University)

Department of Metallurgy and Materials Engineering (University of Connecticut)

Department of Metals and Materials Engineering (University of British Columbia)

Journals

Journal of (the) University of Science and Technology Beijing with subheadings, "Metallurgy" (which covers only extractive aspects) and "Materials" (which includes physical and process metallurgy) 
Georgii Kurdyumov (1902-1996); he was trained as a physicist but became a physical metallurgist. He was neither the first nor the last to make that journey, as interestingly discussed by Merton Flemings, of MIT, in Reference 3.

What can be done to impede our descent down the slippery slope of segregation ... a divorce between those professionally concerned with metals and the rest of the materials community? The U.S. Supreme Court assuredly will not act against this form of segregation: It is for us in the profession to take the necessary steps. This implies the necessity to counteract the ever-present drive to close specialization. Turnbull, in this aforementioned 1983 essay, remarked, "there is a serious danger that these trends [toward specialization] may hinder, or even set back, the interdisciplinary practice and development of Materials Science."

I believe that the most worrying trend is precisely the reactionary pressure to separate the students of metals and alloys from all the rest. This kind of pressure partly, I believe, derives from the falling enrollments in most academic materials science departments in the United States and elsewhere. Flemings, in a recently published lecture, remarked à propos of this, that "some might say this drop exists because our departments have become too diffuse; the departments would have done better to remain focused on metals. But I believe both the historical record and student attitudes tell us that we cannot turn the clock back to metals alone. Others might attribute the drop to the excitement and potential of other fields such as information technology." 4 This particular form of competition has of late become a desperate problem in universities in India.

I have just remarked that labels should be ignored by researchers. Nevertheless, words are important because they can ignite passions. I believe that the Materials Research Society's founders, in 1973, showed great wisdom in using the words "Materials Research" instead of "Materials Science" in its name. For the past 29 years, the Society has (in its own words) "promot[ed] interdisciplinary goal-oriented basic research on materials of technological importance"... an inspired form of words if ever there was one. Whoever contributes to that objective is welcomed with open arms as a member, whatever discipline, or specialty within a discipline, to which he/she subscribes.

I propose that the development most likely to heal the impending breach between metallurgy and MSE is to focus some of the undergraduate teaching in
I believe that the most worrying trend is precisely the reactionary pressure to separate the students of metals and alloys from all the rest.

university MSE programs on courses that center on phenomena that are not specific to one category of materials and also on theoretical approaches that have multiple relevance to various phenomena. A recent textbook from MIT-The Structure of Materials, by Samuel M. Allen and Edwin L. Thomas ${ }^{5}$ - exemplifies what I mean. The key remark in the preface is "throughout the text we use examples from all classes of materials"; the treatment is, in fact, to quote a phrase used by the authors, "materials-catholic." The book focuses on "three different states of solid condensed matter-glasses, crystals and liquid crystals-and develops one set of tools, or structural descriptors, for describing all of them." This is done brilliantly in the book-the discussion of the different classes of liquid crystals is especially illuminating - and the whole treatment succeeds in giving a completely new view of materials science.

An example of a theoretical approach of wide relevance is the theory of random walks, here applied both to diffusion kinetics and to the geometry of polymer chains. The variation of an order parameter with temperature is exemplified by reference to atomic order in alloys and to both orientational and translational order in liquid crystals. The authors might, with advantage, have extended this to the temperature variation of the alignment of magnetic spins and to atomic order in compound semiconductors. Dislocations and disclinations, grain boundaries, and other types of plane discontinuitiesmagnetic domain walls, antiphase boundaries, grain boundaries in block copolymers-demonstrate close parallels that are of clear didactic value. It will probably not be easy to get such textbooks (more are promised) to be widely adopted, and the effort needs to be sustained.

European White Book on Fundamental Research in Materials Science, recently published by the prestigious Max-Planck Institute of Metals Research in Germany, claims, "metallic alloys and composites represent the dominant group of structural and functional materials world wide and within the European Union." 6 Now while this claim is certainly valid for struc- tural materials, it is not true for functional ones. Metals play only a subsidiary role here, and this is one of the considerations that, I believe, lead some to regard metals as not being materials at all. And yet there are important roles for metals in functional devices. An important example is the use of metallic microconductors in integrated circuits-"metallization" for short. There are issues here of fabrication techniques; interdiffusion and its prevention; and microstructural instability, including the complex process of electromigration. Perhaps this kind of subject matter needs more limelight to be cast upon it to reintegrate the study of metallic materials with the rest of materials science.

However the problem is addressed, it is important to recognize that there is a problem here, that it matters, and that it should be dealt with. I hope that the Materials Research Society will be able to help toward that end.

\section{References}

1. M.B. Bever, Metallurgy and Materials Science and Engineering at MIT: 1865-1988 (privately published by the Massachusetts Institute of Technology, Cambridge, MA, 1988).

2. D. Turnbull, "A Commentary on the Emergence and Evolution of 'Materials Science,'" Annu. Rev. Mater. Sci. 13 (1983) p. 1.

3. M.C. Flemings, "What Next for Departments of Materials Science and Engineering?" Annu. Rev. Mater. Sci. 29 (1999) p. 1; specifically, pp. 9-11.

4. M.C. Flemings, "Why Materials Science and Engineering Is Good for Metallurgy," Metall. Mater. Trans. A, 32A (2001) p. 853. Emphasis added.

5. S.M. Allen and E.L. Thomas, The Structure of Materials (Wiley \& Sons, New York, 1998).

6. D. Raabe, "Metals and Composites: Basis for Growth, Safety, and Ecology," in European White Book on Fundamental Research in Materials Science (Max-Planck Institut für Metallforschung, Stuttgart, 2002) p. 21.

Robert W. Cahn, an emeritus professor at Sussex University, became the first professor of materials science in the United Kingdom in 1965. His research has been in physical metallurgy, but much of his writing, editing, and journalism has been concerned with the broad reaches of modern materials science. He received both his first degree, in metallurgy, in 1945 and his doctorate degree in metal physics at Cambridge University, where he settled 20 years ago in nominal retirement. There he has continued with his research and with the editing of a range of books, including a multiauthor three-volume book, Physical Metallurgy, and author of The Coming of Materials Science. He is a fellow of the Royal Society and of five other academies around the world. 